\section{Nickel Content of Deep-Sea Deposits}

INVESTIGations made in this Institute of the ferrides present in sediment cores from great depths, taken by the Swedish Deep-Sea Expedition, have shown their content of nickel to be specially interesting. The only analysis of nickel in deep-sea deposits known to us was published in 1914 by F. W. Clarke and G. Steiger, and gave 0.032 per cent as the content of nickel oxide in a composite sample of red clay from fifty-one different localities ${ }^{1}$. By the aid of modern microanalytical methods (the colour reaction with dimethyl glyoxime) quantitios of nickel as small as 5-6 $\gamma$ can easily be measured.

In a core of red clay from the north-west Atlantic Ocean (lat. $30^{\circ} 29^{\prime}$ N., long. $56^{\circ} 07^{\prime}$ W., depth 5,620 metres, length of core $1,530 \mathrm{~cm}$.) the content of nickel oxide was found to vary between 0.005 and 0.010 per cent, whereas in a red clay core from the central Pacific Ocean (lat. $07^{\circ} 38^{\prime} \mathrm{S}$., long. $152^{\circ} 53^{\prime} \mathrm{W}$, depth 5,000 metres, length of core $1,500 \mathrm{~cm}$.) much higher values were found, ranging between 0.041 and 0.089 per cent of nickel oxide. Assuming the decrease in radium content from the surface layer downwards found in the latter core to be due to the disintegration of ionium, precipitated from the sea-water, namely, a decrease to 50 per cent in 83,000 years, the average rate of deposition in the uppermost parts of the same core would be of the order $0.5 \mathrm{~mm}$. in one thousand years, whereas in the Atlantic core the rate of deposition appears to have been at least ten times higher. The content of nickel oxide in the two cores, therefore, appears to be roughly in inverse proportion to the rate of sedimentation. As is seen from the accompanying graph, where the content of iron-, manganese- and nickel-oxide in the Pacific core is set out as a function of the distance from the top of the core, there are five distinct maxima of nickel content, which do not seem to be related to those of the two other elements.

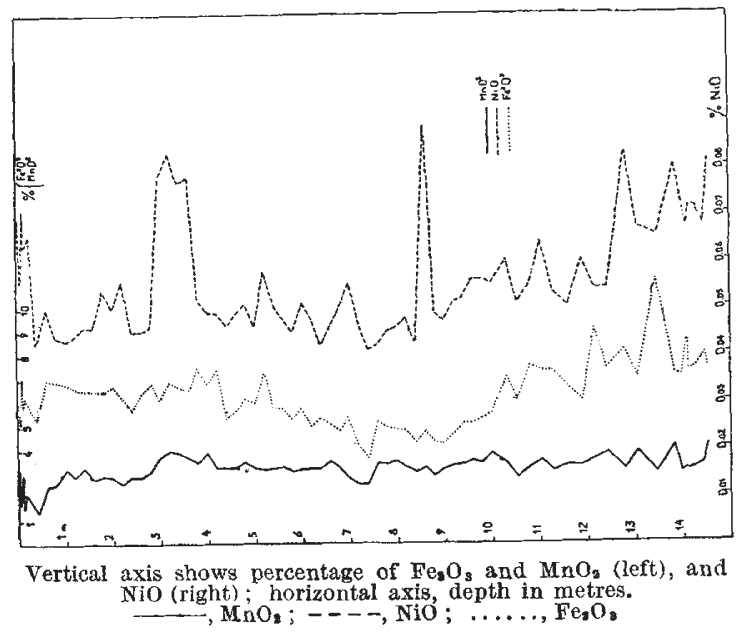

In another Pacific core taken about 400 nautical miles farther south and in a smaller depth, namely, 4,625 metres, there was also a pronounced maximum of nickel oxide in a 'depth' of $223 \mathrm{~cm}$., namely, 0.098 per cent, which possibly corresponds to the uppermost maximum found in the more northerly core.

Regarding the origin of the nickel found by us in the red clay, three different explanations appear possible :
(1) It may have originated from sea water. This, however, appears improbable, considering the extremely low nickel content in the water (about $10^{-8}$ per cent or about 500 times less than its content of iron).

(2) It may have originated from magma spread over the ocean floor by submarine eruptions. Thanks to the courtesy of Dr. S. Landergren of the Geological Survey in Stockholm, we have had various specimens of submarine and supramarine lava from the central Pacific Ocean, as well as basaltic rock fragments, taken from great depths in the Indian Ocean by the John Murray Expedition, analysed for nickel by spectrographic precision methods. The results were low, varying between 0.005 and 0.012 per cent. Further, a layer rich in volcanic minerals taken immediately below the layer of maximum nickel content just mentioned was found to have values similar to those of average samples taken from the same core. A magmatic origin of the high nickel values we have found, although it cannot at present be ruled out, appears, therefore, not very probable.

(3) That the nickel may have originated from meteors and from meteoritic dust, on the other hand, seems worthy of serious consideration. Murray and Renard, in their classical studies of the deposits taken by the Challenger Expedition, recognized a small number of "cosmic spherules" containing nickel-iron in the red clay and other similar deep-sea deposits. It is reasonable to expect that other frag. ments from shooting stars in a metallic or oxidized state, as well as minor fragments of interplanetary dust, drifting into the earth's atmosphere, must be present in the deposits to an extent inversely proportional to the rate of sedimentation. A highly approximate calculation, from what we know at present regarding the nickel content and the rate of sedimentation of the cores we have so far examined, leads to unexpectedly high values for the rate of accretion of meteoric material over the whole earth. Our estimates indicate several thousand tons per day (assuming an average nickel content of 2 per cent by weight), which is considerably more than astronomers are at present prepared to admit, on the basis of visual and telescopic counts of meteors entering the earth's atmosphere.

Should a cosmic origin of at least the greater part of the nickel found in the red clay be accepted as a working hypothesis, special interest is attached to the maxima shown by the curve. They might be explained as indicating occurrences of an increased frequency of meteors in the past, possibly due to the solar system travelling through relatively dense cosmic clouds, affording increased chances of captur. ing comets and meteors.

Investigations now being undertaken will have to show whether such maxima of nickel content coincide with maxima in the number of cosmic spherules, and whether they are of world-wide occurrence. Anyhow, it appears desirable to submit future deep-sea cores to a systematic search for nickel.

Hans Pettersson Henri Rotschi

Oceanografiska Institutet, Göteborg. May 29.

${ }^{1}$ Clarke, F. W., and Steiger, G., J. Washington Acad. Sei., 4, 58 (1914). 